\title{
Zum Problem der tuberkulösen Kaverne
}

\begin{tabular}{|l|l|l|}
\hline E. & Haefliger \\
\hline
\end{tabular}

\section{Wald}

Adresse des Autors: Dr. E. Haefliger, Zürcher Heilstätte, Wald.

Erscheínt anderwärts

Dískussíon

Galy: bei der anatomischen Untersuchung von Resektionsprä-paraten findet man bei den nicht ausgeheilten Restkavernen immer Pleuraverwachsungen und ein Fortbestehen von

Dränagebronchien in den oberen Partien der Kavernen, während die Bronchien im untern

Abflußgebiet oft schon verschlossen sind. Es findet sich nie Epithelisation der Kavernen.

Tanner: die endobronchiale Absaugung bringt nur ausnahms-weise Erfolg, meist nur kurzdauernde Verkleinerung der Kaverne und rasche Wiederaufblähung derselben. Studer: In diesen Fallen ist die Anlage der Saugdränage nach Monaldi zu empfehlen. Sturzenegger: der Verschluß der Höhle erfolgt nur, wenn der Ableitungsbronchus sich schließt, der Monaldi führt aber im Gegen-teil zum Offenbleiben der Kaverne.

Herzog: oft ist eine asthmatische Komponente für die Blähung der Kaverne verantwortlich infolge Bronchiolospasmus und Ventil-mechanismus. Atemtherapie und Aleudrin-Inhalationen führten zur Verkleinerung der Kavernen.

Kreuser: Intrakavitäre Instillation von Conteben bringt manch-mal Erfolg.

Tanner: Es fragt sich, ob nicht die Behandlung mit Steroiden die narbige Obliteration der Dränagebronchien verhindert.

Barras: Die Monaldidränage ist in diesen zwei Fallen wertvoll. Oft findet sich in den Fallen von Restkavernen eine Begleitbron-chitis. 